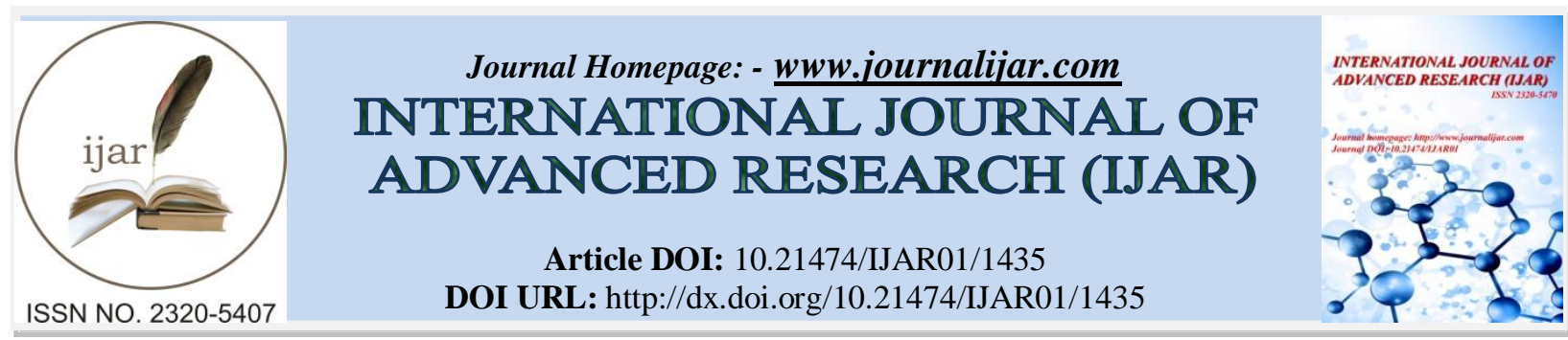

RESEARCH ARTICLE

\title{
A NEW RP-HPLC METHOD DEVELOPMENT AND VALIDATION OF DEFERIPRONE IN BULK AND ITS PHARMACEUTICAL DOSAGE FORM.
}

\author{
K. Sai Sireesha*, B. Siva sai kiran, K.B. Chandra Sekhar, Shaik Muneer. \\ Department of Pharmaceutical Sciences, JNTUA-Oil Technological and Pharmaceutical Research Institute \\ (OTPRI), Ananthapuramu, A.P, India.
}

\section{Manuscript Info}

Manuscript History

Received: 12 June 2016

Final Accepted: 19 July 2016

Published: August 2016

Key words:-

RP-HPLC, Deferiprone, ICH guidelines.

\section{Abstract}

A simple, precise, new RP-HPLC method was developed and validated for the determination of Deferiprone in bulk and its pharmaceutical dosage form. In this method separation of liquid was done by using column $\mathrm{C} 18$, with mobile phase of water and Acetonitrile in the ratio of $55: 45 \mathrm{v} / \mathrm{v}$ ratio. The detection wavelength was found to be $280 \mathrm{~nm}$ with a flow rate of $1 \mathrm{ml} / \mathrm{min}$ and temperature of $30^{\circ} \mathrm{c}$. Retention time of Deferiprone was $4.960 \mathrm{~min}$. The proposed method was validated as per standard guidelines. In the range of $10 \mu \mathrm{g}$ to $50 \mu \mathrm{g} / \mathrm{ml}$ the linearity of Deferiprone shows a co-relation coefficient of 0.999 . precision was found $\%$ RSD to be 0.70 . The $\%$ mean recovery of Deferiprone was found to be $98.40 \%$. The method was found to be robust even by changing in the flow rate of $0.2 \mathrm{ml} / \mathrm{min}$ and wavelength of $\pm 2 \mathrm{~nm}$. The developed method can be successfully employed for the routine analysis of Deferiprone in pharmaceutical dosage forms.

Copy Right, IJAR, 2016,. All rights reserved.

\section{Introduction:-}

Deferiprone is chemically 3-Hydroxy-1,2-dimethyl-4(1H)-pyridone ${ }^{[1]}$. It is an oral iron chelator that binds to ferric ions (iron III) and forms a 3:1 (deferiprone: iron) stable complex, and used as a second line agent in thalassemia syndromes when iron overload from blood transfusions occurs. As a result, erythropoiesis, the production of new red blood cells, is impaired. It is more selective for iron in which other metals such as zinc, copper, and aluminum have a lower affinity, and route of elimination is through urine ${ }^{[2]}$.

A thorough literature survey reveals that only single liquid chromatographic ${ }^{[3]}$ and spectrophotometric method ${ }^{[4-6]}$ were reported for the determination of deferiprone. The present study is designed to develop simple, economic, accurate and validated RP-HPLC method for the quantification of deferiprone in bulk and its pharmaceutical dosage form. The chemical structure of deferiprone was shown in Fig. 1.

\section{Materials and methods:-}

\section{Instruments:-}

RP-HPLC instrument Shimadzu, LC-20 AD equipped with a PDA detector was used. Chromatograms were automatically obtained by LC-solution system software.

Corresponding Author:- K. Sai Sireesha

Address:- Department of Pharmaceutical Sciences, JNTUA-Oil Technological and Pharmaceutical

Research Institute (OTPRI), Ananthapuramu, A.P, India. 


\section{Reagents and Chemicals:-}

An analytically pure sample of Deferiprone was procured as gift sample from Cipla Ltd, Hyderabad, India. HPLC grade methanol, water and acetonitrile were purchased from SD fine chem. Limited, Mumbai, India. Deferiprone capsule formulation [KELFER ${ }^{\circledR}$ containing $250 \mathrm{mg}$ of drug content, Cipla Ltd, Hyderabad, India] was procured from a local pharmacy.

\section{Liquid chromatographic conditions:-}

Chromatographic separations were obtained by isocratic mode which was performed using a mobile phase containing Water and Acetonitrile in the ratio of $55: 45 \%(\mathrm{v} / \mathrm{v})$ at a flow rate of $1 \mathrm{ml} / \mathrm{min}$ through $\mathrm{C} 18$ Phenomenx luna column. The selective detection of the column effluent was monitored at a wavelength of $280 \mathrm{~nm}$. Injection volume was $20 \mu 1$.

\section{Preparation of standard stock solution:-}

$100 \mathrm{mg}$ of standard Deferiprone was weighed accurately and transferred to $100 \mathrm{ml}$ volumetric flask. Drug was dissolved in $50 \mathrm{ml}$ of mobile phase with sonication for $15 \mathrm{~min}$ and then volume was made up to the mark with mobile phase. Further the stock solutions were diluted to get $100 \mu \mathrm{g} / \mathrm{ml}$ final concentration of standard stock solution of drug. This stock solution was filtered through $0.4 \mu$ membrane filter paper.

\section{Preparation of sample solution:-}

20 capsules of DEP were weighed separately and average weight was determined. A weight of powder equivalent to $100 \mathrm{mg}$ was accurately weighed and transferred to $100 \mathrm{ml}$ volumetric flask, dissolved in 50ml of mobile phase and sonicated for $15 \mathrm{~min}$.make up to the mark with mobile phase further dilutions were prepared using mobile phase as a diluent.

\section{Validation of the proposed method:-}

The proposed method was validated according to the International Conference on Harmonization (ICH) guidelines [7].

\section{Linearity and range:-}

The linearity of calibration curves in pure solutions were checked over the concentration ranges of about 10-50 $\mu \mathrm{g} / \mathrm{ml}$ for deferiprone. The regression line relating standard concentrations of drug using regression analysis, the calibration curves were linear in the studied range and the equations of the regression analysis were obtained: $y=165.2 x-74.30, R^{2}=0.999$. The linearity plots were shown in figure 2 .

\section{Accuracy:-}

Accuracy of the method was determined by Recovery studies. To the formulation (pre analyzed sample), the reference standards of the drugs were added at the level of $80 \%, 100 \%, 120 \%$. The recovery studies were carried out three times and the percentage recovery and percentage mean recovery were calculated for drug is shown in table. To check the accuracy of the method, recovery studies were carried out by addition of standard drug solution to preanalyzed sample solution at three different levels $80 \%, 100 \%$ \& $120 \%$.

\section{Precision:-}

\section{Precision (Repeatability):-}

The precision of the instrument was checked by repeated scanning and measurement of absorbance of solutions $(\mathrm{n}=$ 6) for Deferiprone without changing the parameter of the proposed chromatographic method

\section{Intermediate precision:-}

The intraday and interday precision of the proposed method was determined by analyzing the corresponding responses 3 times on the same day and on 3 different days over a period of 1 week for 3 different concentrations of standard solutions of Deferiprone. The result was reported in terms of relative standard deviation (\% RSD).

\section{Robustness:-}

\section{Chromatographic conditions variation:-}

To demonstrate the robustness of the method, prepared solution as per test method and injected at different variable conditions like using different conditions like flow rate and wavelength. System suitability parameters were compared with that of method precision. No significant change was observed. 


\section{Ruggedness:-}

The ruggedness of the method was studied by the determining the analyst to analyst variation by performing the Assay by two different analysts

\section{Limit of detection and Limit of quantification:-}

The limit of detection (LOD) and the limit of quantification (LOQ) of the drug were derived by calculating the signal-to-noise ratio ( $\mathrm{S} / \mathrm{N}$, i.e., 3.3 for $\mathrm{LOD}$ and 10 for $\mathrm{LOQ}$ ) using the following equations designated by International Conference on Harmonization (ICH) guidelines.

$$
\begin{aligned}
& L O D=3.3 \times \sigma / S \\
& L O Q=10 \times \sigma / S
\end{aligned}
$$

Where, $\sigma=$ the standard deviation of the response and $\mathrm{S}=$ slope of the calibration curve.

\section{Results and Discussion:-}

The regression analysis data and validation parameters for the methods are shown in (Table 1). The calibration curve for Deferiprone is shown in (Figure 2). The method was found to be precise and accurate which was evident from its low \%RSD values (Table 2 and 3). The results of the assay are shown in the (Table 4). Results of robustness study are shown in (Table 5). The results for system suitability are shown in (Table 6). Chromatogram of Standard Deferiprone is shown in the (Figure 3).

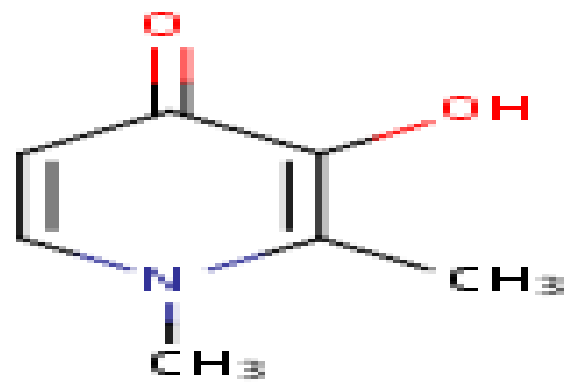

Figure 1:- Chemical structure of deferiprone.

\begin{tabular}{|c|c|c|}
\hline \multicolumn{2}{|c|}{ Parameter } & Result \\
\hline \multicolumn{2}{|c|}{ Linearity range } & $10-50 \mu \mathrm{g} / \mathrm{ml}$ \\
\hline \multicolumn{2}{|c|}{ Slope } & 165.2 \\
\hline \multicolumn{2}{|c|}{ Intercept } & 74.03 \\
\hline \multicolumn{2}{|c|}{$\frac{\mathrm{R}^{2}}{\text { Intraday precision }}$} & 0.999 \\
\hline & & 0.70 \\
\hline \multicolumn{2}{|c|}{ Interday precision } & 0.68 \\
\hline \multirow[t]{3}{*}{ Accuracy } & $80 \%$ & $98.40 \%$ \\
\hline & $100 \%$ & $98.98 \%$ \\
\hline & $120 \%$ & $98.10 \%$ \\
\hline \multicolumn{2}{|c|}{ Limit of detection } & $0.0659 \mu \mathrm{g} / \mathrm{ml}$ \\
\hline \multirow{2}{*}{\multicolumn{2}{|c|}{$\begin{array}{c}\text { Limit of quantification } \\
\text { \%Assay }\end{array}$}} & $0.199 \mu \mathrm{g} / \mathrm{ml}$ \\
\hline & & $99.63 \%$ \\
\hline
\end{tabular}

Table 1:- Regression analysis data and summary of validation parameters for the proposed method. 
Table 2:- Intraday and inter-day precision studies.

\begin{tabular}{|c|c|c|}
\hline S.No. & Inter day precision Area & Intraday precision Area \\
\hline 1 & 3059.295 & 3021.250 \\
\hline 2 & 3091.558 & 3068.995 \\
\hline 3 & 3314.065 & 3432.658 \\
\hline 4 & 3293.678 & 3697.549 \\
\hline 5 & 3067.163 & 3249.339 \\
\hline 6 & 3315.153 & 3093.478 \\
\hline Avg & 3290.152 & 3260.576 \\
\hline Stdev & 23.203 & 22.409 \\
\hline \%RSD & $\mathbf{0 . 7 0}$ & $\mathbf{0 . 6 8}$ \\
\hline
\end{tabular}

Table 3:- Recovery Studies of deferiprone.

\begin{tabular}{|c|c|c|c|c|c|c|}
\hline \multirow{2}{*}{$\begin{array}{l}\text { Recovery } \\
\text { level }\end{array}$} & \multicolumn{5}{|c|}{ Accuracy Deferiprone } & \multirow{2}{*}{$\begin{array}{l}\text { Average } \% \\
\text { Recovery }\end{array}$} \\
\hline & $\begin{array}{l}\text { Amount } \\
\text { taken }(\mathrm{mcg} / \mathrm{ml})\end{array}$ & Area & $\begin{array}{l}\text { Average } \\
\text { area }\end{array}$ & $\begin{array}{l}\text { Amount recovered } \\
(\mathrm{mcg} / \mathrm{ml})\end{array}$ & \%Recovery & \\
\hline \multirow[t]{3}{*}{$80 \%$} & 80 & 3404.393 & \multirow[t]{3}{*}{3256.777} & \multirow[t]{3}{*}{73.60} & \multirow[t]{3}{*}{98.14} & \multirow{9}{*}{98.40} \\
\hline & 80 & 3069.834 & & & & \\
\hline & 80 & 3296.104 & & & & \\
\hline \multirow[t]{3}{*}{$100 \%$} & 100 & 3838.430 & \multirow[t]{3}{*}{3483.758} & \multirow[t]{3}{*}{98.98} & \multirow[t]{3}{*}{98.98} & \\
\hline & 100 & 3285.170 & & & & \\
\hline & 100 & 3327.673 & & & & \\
\hline \multirow[t]{3}{*}{$120 \%$} & 120 & 4838.317 & \multirow[t]{3}{*}{4760.862} & \multirow[t]{3}{*}{122.63} & \multirow[t]{3}{*}{98.10} & \\
\hline & 120 & 4781.051 & & & & \\
\hline & 120 & 4663.219 & & & & \\
\hline
\end{tabular}

Table 4;- Analysis of Deferiprone in marketed formulation.

\begin{tabular}{|c|c|c|}
\hline \multicolumn{3}{|c|}{ DEFERIPRONE } \\
\hline & Standard Area & Sample Area \\
\hline Injection-1 & 3323.905 & 3315.153 \\
\hline Injection-2 & 3320.771 & 2958.634 \\
\hline Injection-3 & 3293.678 & 3099.478 \\
\hline Injection-4 & 3274.549 & 3304.543 \\
\hline Injection-5 & 3193.689 & 3148.994 \\
\hline Average Area & 3281.318 & $0.30132 \mathrm{gm}$ \\
\hline Capsule average weight & \multicolumn{2}{|c|}{$0.0120 \mathrm{mg}$} \\
\hline Standard weight & \multicolumn{3}{|c|}{$250 \mathrm{mg}$} \\
\hline Sample weight & $\mathbf{9 9 . 6 3}$ \\
\hline Label amount & \multicolumn{3}{|c|}{} \\
\hline Assay(\%purity) & \\
\hline
\end{tabular}

Table 5:- Results of Robustness study.

\begin{tabular}{|c|c|c|}
\hline \multirow{2}{*}{ Parameter } & \multicolumn{2}{|c|}{ Deferiprone } \\
\cline { 2 - 3 } & Retention time(min) & Tailing factor \\
\hline Flow & & \\
$\mathbf{0 . 8 m l} / \mathbf{m i n}$ & 6.080 & 1.783 \\
$\mathbf{1 . 0} \mathbf{~ m l} / \mathbf{m i n}$ & 4.950 & 1.667 \\
$\mathbf{1 . 2} \mathbf{m l} / \mathbf{m i n}$ & 4.233 & 1.588 \\
& & \\
\hline Wavelength & 4.973 & 1.641 \\
$\mathbf{2 7 8 n m}$ & 4.950 & 1.667 \\
$\mathbf{2 8 0 n m}$ & 4.963 & 1.641 \\
\hline $\mathbf{2 8 2 n m}$ & & \\
\hline
\end{tabular}


Table 6:- Results of System suitability parameters.

\begin{tabular}{|c|c|}
\hline Parameter & Result \\
\hline Retention time & $4.960 \mathrm{~min}$ \\
\hline Tailing factor & 1.641 \\
\hline Theoretical plate & 4207 \\
\hline
\end{tabular}

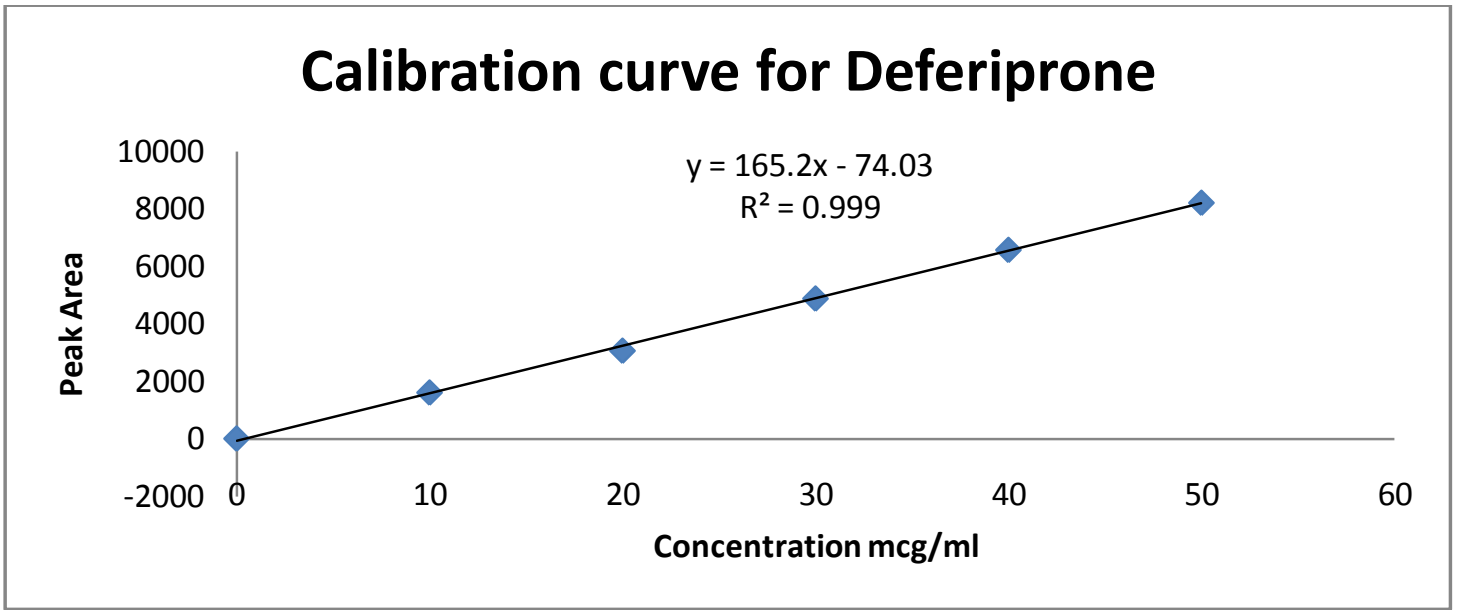

Fig 2:- Calibration curve of deferiprone.

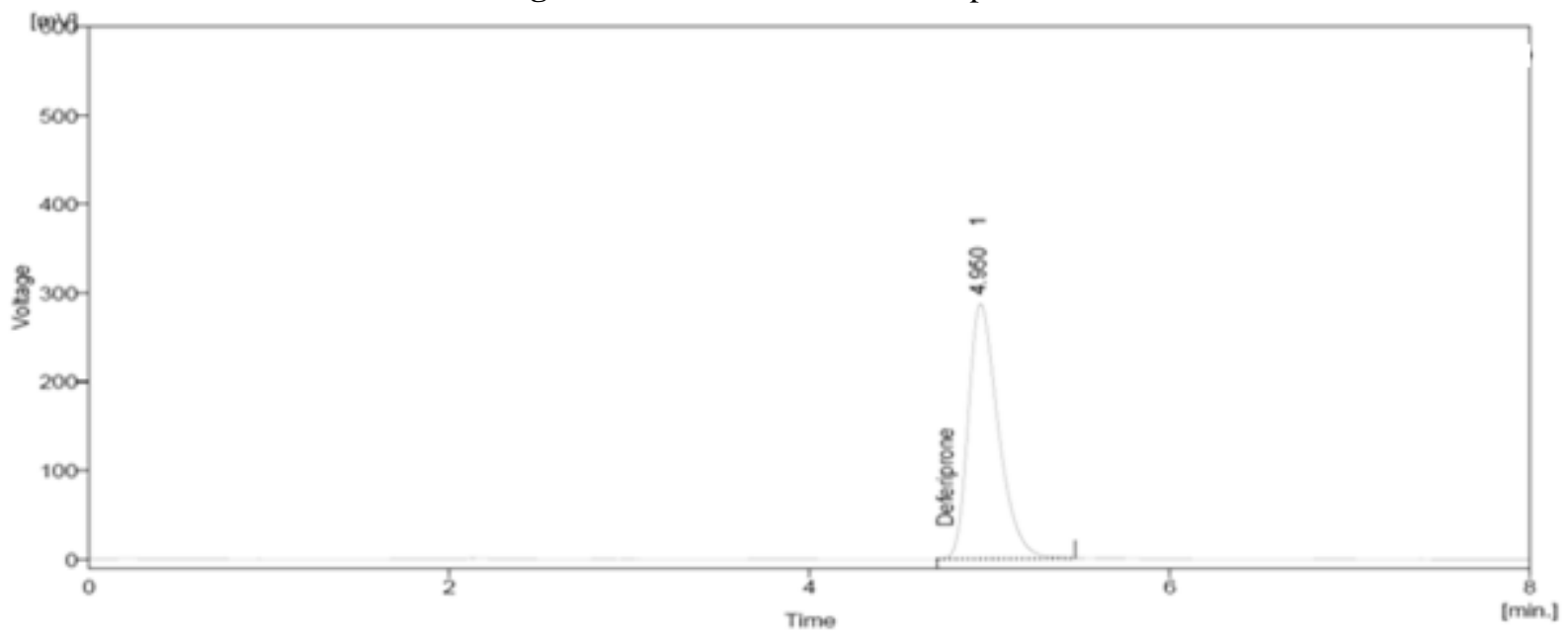

Fig 3:- Chromatogram of Deferiprone. 


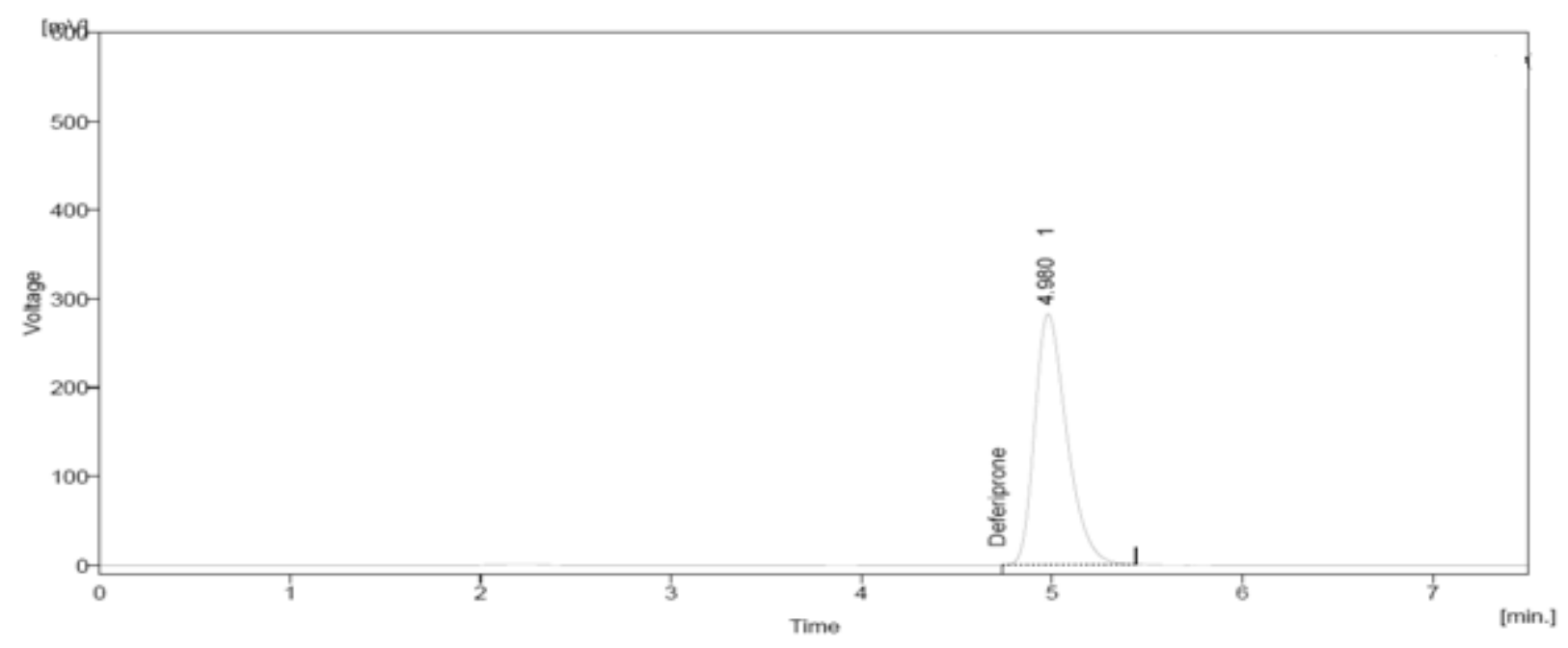

Fig 4:- Standard chromatogram of Deferiprone.

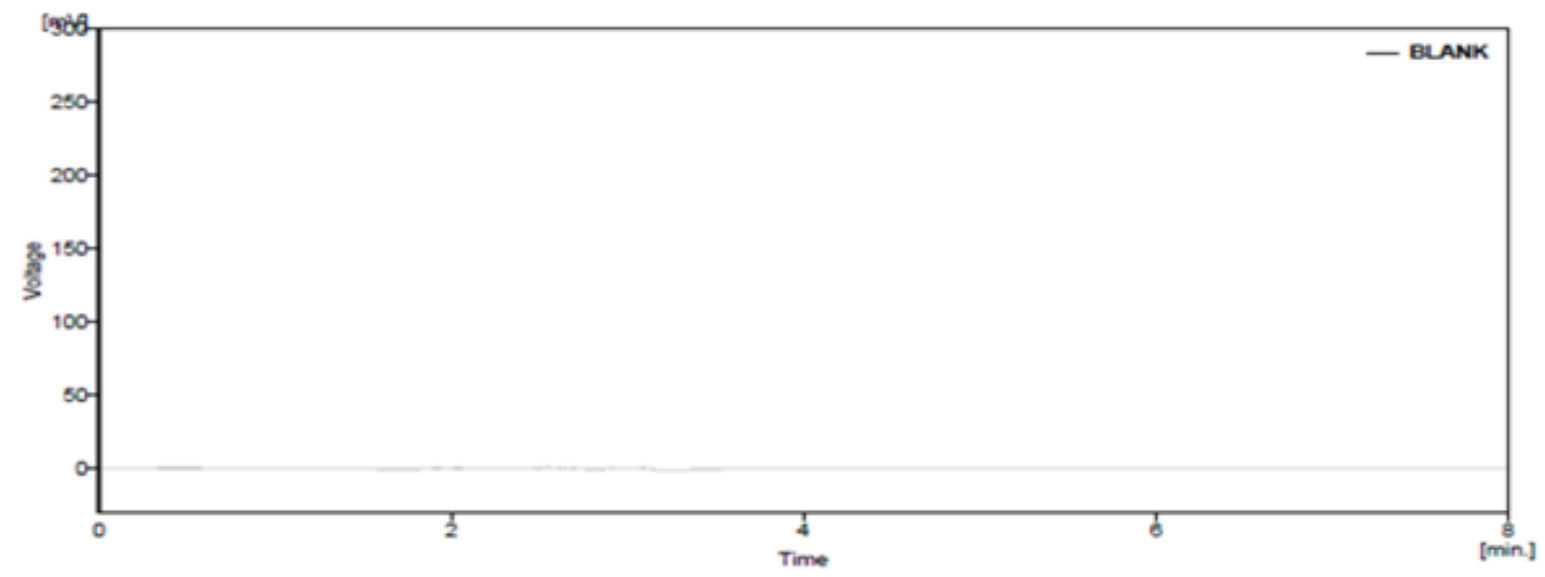

\section{Conclusion:-}

Fig 5:- Chromatogram of baseline.

A simple and selective LC method is described for the determination of Deferiprone dosage forms. Chromatographic separation was achieved on a $\mathrm{c}_{18}$ column using mobile phase consisting of a mixture of HPLC

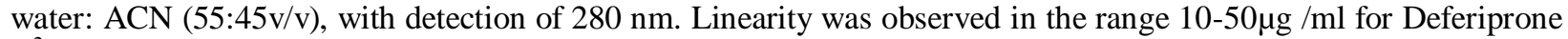
$\left(\mathrm{r}^{2}=0.999\right)$. The amount of drug estimated by the proposed methods was in good agreement with the label claim. The method can be used for the routine analysis of deferiprone in dosage forms without any interference of excipients.

\section{References:-}

1. http://www.drugbank.ca/drugs/DB08826.

2. https://en.wikipedia.org/wiki/Deferiprone.

3. Hinesha Barot, Darshil Shah, Dr. DilipMaheshwari. Development of stability indicating UV Spectroscopy method development for the estimation of deferiprone in pharmaceutical formulation. Am. J. PharmTech Res, 5(1), 2015, 622-632.

4. Manzoor Ahmed, Vinod Kumar Jangade, Satishkumar Shetty A, Vijaya Krishna C. Aradhya, Anil Kumar S.M. Development and validation of first order derivative spectrophotometric method for the estimation of deferiprone in bulk and capsule dosage form.Int.J.of universal pharmacy and biosciences. 4(3), 2015, 169-176.

5. Manzoor Ahmed, Vinod Kumar Jangade*, Satishkumar Shetty A, Vijayakrishna C. Aradhya, Kuppast I.J and Anil kumar S.M. RP-HPLC method development and validation for estimation of deferiprone in capsule dosage form. World Journal of Pharmacy and Pharmaceutical Sciences. 4(3), 2015, 831-838.

6. Mateen Abbas, Rakhshanda Nawaz, Tahira Iqbal2, Muhammad Alim, Muhammad Rafique Asi. Quantitative determination of deferiprone in human plasma by reverse phase high performance liquid chromatography and its application to pharmacokinetic study. Pak. J. Pharm. Sci.25(2), 2012, 343-348.

7. Validation of analytical procedure:text and methodology, in. international conference on harmonization(ICH), Q2 (R1), IFPMA, Geneva, Switzerland, 2005. 